\title{
Retroperitoneal hamartoma in a pediatric patient
}

\author{
Omar M. Javery • Edward Y. Lee
}

Received: 13 October 2009 /Revised: 7 March 2010 / Accepted: 25 March 2010 /Published online: 27 April 2010

(C) Springer-Verlag 2010

A 13-year-old boy presented with vague abdominal pain and a palpable mass in the right abdomen. US revealed a large heterogeneous retroperitoneal mass $(M)$, displacing the right kidney superiorly $(K)$ (Fig. 1). Subsequently, a coronal enhanced CT showed a large heterogeneously enhancing mass with internal vessels (arrow) and areas of low attenuation (curved arrow) indicative of adipose tissue (Fig. 2). Also noted is the superiorly displaced right kidney (Fig. 2). Surgical pathology was consistent with a benign hamartoma, consisting of disorganized fatty, vascular, and fibrous components. Genetic analysis revealed a mutation in the phosphatase and tensin homologue (PTEN) gene.

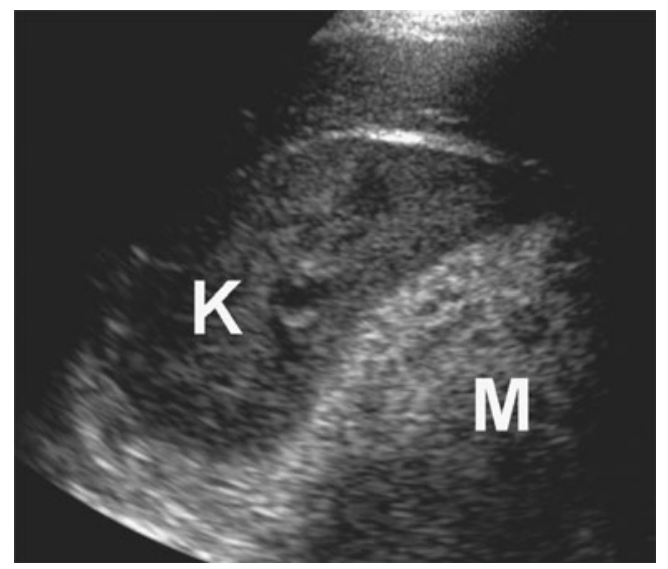

Fig. 1 US

\section{O. M. Javery}

Department of Radiology,

Brigham and Women's Hospital and Harvard Medical School,

Boston, MA, USA

\section{E. Y. Lee $(\bowtie)$}

Department of Radiology,

Children's Hospital Boston and Harvard Medical School,

300 Longwood Ave.,

Boston, MA 02115, USA

e-mail: Edward.Lee@childrens.harvard.edu

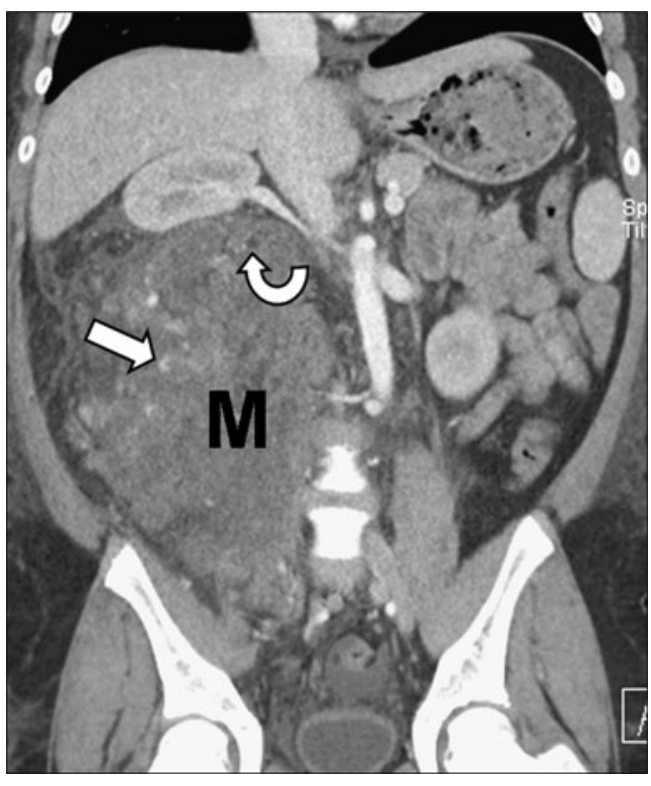

Fig. 2 Coronal enhanced CT

PTEN is a tumor suppressor gene recently implicated in a collection of disorders termed the PTEN hamartoma-tumor syndrome [1, 2]. Affected individuals are at risk for developing various benign and malignant tumors $[1,2]$. In addition, PTEN has been linked with vascular anomalies [2]. Given the extent of the tumor and the potential for substantial morbidity with surgical resection, surgical removal of the mass is currently deferred in this boy.

\section{References}

1. Eng C (2003) PTEN: one gene, many syndromes. Hum Mutation 22:183-198

2. Tan W, Baris HN, Burrows PE et al (2007) The spectrum of vascular anomalies in patients with PTEN mutations: implications for diagnosis and management. J Med Genet 44:594-602 